\section{OPEN ACCESS}

Edited by:

Judit Hohmann,

University of Szeged, Hungary

Reviewed by:

Linlin Lu,

International Institute for Translational

Chinese Medicine, China

Codruta Soica

Victor Babeș University of Medicine and Pharmacy, Timisoara, Romania

*Correspondence:

Georg Krupitza

georg.krupitza@meduniwien.ac.at

Liselotte Krenn

liselotte.krenn@univie.ac.at

Specialty section:

This article was submitted to

Ethnopharmacology,

a section of the journal

Frontiers in Pharmacology

Received: 05 October 2017

Accepted: 27 February 2018

Published: 14 March 2018

Citation:

Hong J, Fristiohady A, Nguyen $\mathrm{CH}$, Milovanovic D, Huttary N, Krieger S, Hong J, Geleff S, Birner P, Jäger W,

Özmen A, Krenn L and Krupitza $G$ (2018) Apigenin and Luteolin

Attenuate the Breaching of MDA-MB231 Breast Cancer Spheroids Through the Lymph Endothelial Barrier in Vitro. Front. Pharmacol. 9:220. doi: 10.3389/fphar.2018.00220

\title{
Apigenin and Luteolin Attenuate the Breaching of MDA-MB231 Breast Cancer Spheroids Through the Lymph Endothelial Barrier in Vitro
}

\author{
Junli Hong 1,2,3, Adryan Fristiohady $3,4,5$, Chi H. Nguyen ${ }^{3,4}$, Daniela Milovanovic ${ }^{3}$, \\ Nicole Huttary ${ }^{3}$, Sigurd Krieger ${ }^{3}$, Junqiang Hong ${ }^{6}$, Silvana Geleff ${ }^{3}$, Peter Birner ${ }^{3}$, \\ Walter Jäger ${ }^{4}$, Ali Özmen ${ }^{7}$, Liselotte Krenn ${ }^{1 *}$ and Georg Krupitza ${ }^{3 *}$
}

\begin{abstract}
1 Department of Pharmacognosy, Faculty of Life Sciences, University of Vienna, Vienna, Austria, ${ }^{2}$ School of Pharmacy, Nanjing Medical University, Nanjing, China, ${ }^{3}$ Clinical Institute of Pathology, Medical University of Vienna, Vienna, Austria, ${ }^{4}$ Department for Clinical Pharmacy and Diagnostics, Faculty of Life Sciences, University of Vienna, Vienna, Austria,

${ }^{5}$ Faculty of Pharmacy, Halu Oleo University, Kendari, Indonesia, ${ }^{6}$ Department of Medical Oncology, The 188th Hospital of People's Liberation Army of China, Chaozhou, China, ${ }^{7}$ Department of Biology, Faculty of Science and Art, Adnan Menderes University, Aydin, Turkey
\end{abstract}

Flavonoids, present in fruits, vegetables and traditional medicinal plants, show anticancer effects in experimental systems and are reportedly non-toxic. This is a favorable property for long term strategies for the attenuation of lymph node metastasis, which may effectively improve the prognostic states in breast cancer. Hence, we studied two flavonoids, apigenin and luteolin exhibiting strong bio-activity in various test systems in cancer research and are readily available on the market. This study has further advanced the mechanistic understanding of breast cancer intravasation through the lymphatic barrier. Apigenin and luteolin were tested in a three-dimensional (3-D) assay consisting of MDA-MB231 breast cancer spheroids and immortalized lymph endothelial cell (LEC) monolayers. The 3-D model faithfully resembles the intravasation of breast cancer emboli through the lymphatic vasculature. Western blot analysis, intracellular $\mathrm{Ca}^{2+}$ determination, EROD assay and siRNA transfection revealed insights into mechanisms of intravasation as well as the anti-intravasative outcome of flavonoid action. Both flavonoids suppressed pro-intravasative trigger factors in MDA-MB231 breast cancer cells, specifically MMP1 expression and CYP1A1 activity. A pro-intravasative contribution of FAK expression in LECs was established as FAK supported the retraction of the LEC monolayer upon contact with cancer cells thereby enabling them to cross the endothelial barrier. As mechanistic basis, MMP1 caused the phosphorylation (activation) of FAK at Tyr397 in LECs. Apigenin and luteolin prevented MMP1-induced FAK activation, but not constitutive FAK phosphorylation. Luteolin, unlike apigenin, inhibited MMP1-induced $\mathrm{Ca}^{2+}$ release. Free intracellular $\mathrm{Ca}^{2+}$ is a central signal amplifier triggering LEC retraction through activation of the mobility protein MLC2, thereby enhancing intravasation. FAK activity and $\mathrm{Ca}^{2+}$ levels did not correlate. This implicates that the pro-intravasative contribution of FAK and of $\mathrm{Ca}^{2+}$ release in LECs was independent of each other and explains the better anti-intravasative effects 
of luteolin in vitro. In specific formulations, flavonoid concentrations causing significant anti-intravasative effects, can certainly be achieved in vivo. As the therapeutic strategy has to be based on permanent flavonoid treatment both the beneficial and adverse effects have to be investigated in future studies.

Keywords: intravasation, 3D model, flavonoids, FAK, MMP1, CYP1A1, $\mathrm{Ca}^{2+}$ release

\section{INTRODUCTION}

Species of the Scrophularia family are used in ethno-medicine since ancient times (Galindez et al., 2002). In the search for anti-metastatic natural compounds, extracts of six Scrophularia species were tested. For a methanolic extract from S. lucida a significant anti-intravasative activity was discovered (Giessrigl et al., 2012). The chloroform fraction of the methanolic extract inhibited in vitro intravasation of breast cancer spheroids most effectively. The major compound of the most active sub-fraction was hispidulin which, as pure compound, attenuated this early stage of the metastatic process significantly (Lewenhofer et al., 2018, same issue). Therefore, we decided to test two structurally related flavonoids, luteolin and apigenin, in in-depth mechanistic studies. These flavonoids are present in many medicinal plants used in the traditional medicine of Central and Eastern Europe. One of the oldest references to a healing plant in occidental literature can be found in Homer's Iliad (book XI, line 822 et seq.; Murray, 1924). There is said that 'A $A\llcorner\lambda \lambda \varepsilon \dot{s} \varsigma$ used a bitter, astringent root to treat wounds. This background in mythology led to the name of a very important medicinal plant: Achillea. In fact, this plant is used to treat, among other ailments, bleeding disorders and bruises (Akram, 2013). Later, Achillea sp. ("Achilleios") was also listed in De Materia Medica; Dioscurides, 1st century A.D. and used by Classical Greeks, in the Roman Empire, the Byzantium, and the Middle Ages up until our present day. A. millefolium is very rich in glycosides of luteolin and apigenin, which are easily metabolized into the respective genins (Benedek et al., 2007; Benetis et al., 2008). Many other apigenin- and luteolin-rich plant genera are also listed in $D e$ Materia Medica: Cynara, Apium, Allium, Petroselinum, Punica, Thymus, Solidago, Chamaemelum, Viola, and Vitis (the entire $5^{\text {th }}$ book is dedicated to Vitis).

Triple negative breast cancer (TNBC) comprises about 15\% of all breast cancer types. In general, TNBC responds well to chemotherapy as long it has not disseminated to other organs. However, as soon as TNBC metastasizes the success of drug treatment is very limited. This implicates that TNBC, in addition to conventional therapy, needs a metastasis-preventive approach to maintain a tumor state associated with a better prognosis. At an early stage of metastasis breast cancer cells intravasate the lymphatic vasculature and colonize lymph nodes. Importantly, the "lymph node status" is a prognostic breast tumor marker (Sobin et al., 2009). Hence, we hypothesized that compounds which prevent intravasation may interfere with tumor progression such as lymph node- and distant organ metastasis. As such a preventive concept for TNCB has to be based on long term drug administration, the therapeutic regimen has to be mild and rather free of side effects to allow continuous treatment. Luteolin inhibited proliferation and induced apoptosis of the highly metastatic TNBC cell line MDA-MB231 (Attoub et al., 2011). Anti-invasive/anti-metastatic activities of luteolin (Tsai et al., 2016; Lin et al., 2017) and the structurally related analog apigenin (Lindenmeyer et al., 2001; Qin et al., 2016; Zhao et al., 2017) have also been demonstrated in various cancer cell lines. As these flavonoids are also wide-spread constituents in fruits and vegetables they are considered free of adverse effects. This tempted us to investigate luteolin and apigenin in terms of their anti-intravasative properties. In the daily diet, the concentration of flavonoids is too low to show tumor preventive effects (Vogiatzoglou et al., 2015). However, apigenin and luteolin are also commercially available as food supplements with rather high concentrations (40-200 mg apigenin/capsule; $50 \mathrm{mg}$ luteolin/capsule) and may provide a preventive option.

The TNCB cell line MDA-MB231 over-expresses the pro-metastatic matrix metalloprotease 1 (MMP1), and inhibition of MMP1 attenuates tumor intravasation (Nguyen et al., 2015). Furthermore, MDA-MB231 cells secrete the pro-intravasative arachidonic acid metabolite 12(S)-HETE (Nguyen et al., 2016a), which is synthesized by CYP1A1. Therefore, we investigated whether luteolin and apigenin interfered with MMP1 expression and CYP1A1 activity in MDA-MB231 cells.

MMP1 and 12(S)-HETE activate the PAR1 and the 12(S)-HETE receptor, respectively, in LECs, which both trigger the release of $\mathrm{Ca}^{2+}$, causing the rapid retraction of LECs. This opens gaps in the monolayer [circular chemorepellent-induced defects (CCIDs)] through which tumor cells cross the endothelial barrier (Nguyen et al., 2015, 2016b). Hence, the influence of apigenin and luteolin on levels of intracellular $\mathrm{Ca}^{2+}$ in LECs was investigated. The expression of FAK in LECs seems to be crucial for rapid cell movement (Desai et al., 2009) as observed during CCID formation. Thus, FAK expression and activity were studied as well.

\section{MATERIALS AND METHODS}

\section{Antibodies and Reagents}

Polyclonal rabbit anti-focal adhesion kinase (FAK) and polyclonal rabbit anti-phospho-Tyr397-FAK were purchased from Cell Signaling (Danvers, MA, United States), polyclonal rabbit anti-MMP1 from Abcam (Cambridge, United Kingdom) and monoclonal anti- $\beta$-actin from Sigma (Munich, Germany). Polyclonal rabbit anti-mouse, anti-goat and anti-rabbit IgGs were acquired from Dako (Glostrup, Denmark). Apigenin and luteolin were purchased from Sigma (Munich, Germany) and human recombinant MMP1 from Sigma-Aldrich (SRP3117, 
<smiles>O=c1cc(-c2ccc(O)cc2)oc2cc(O)cc(O)c12</smiles><smiles>O=c1cc(-c2ccc(O)c(O)c2)oc2cc(O)cc(O)c12</smiles>

\section{c Treatment of the MDA/LEC model with apigenin and luteolin}

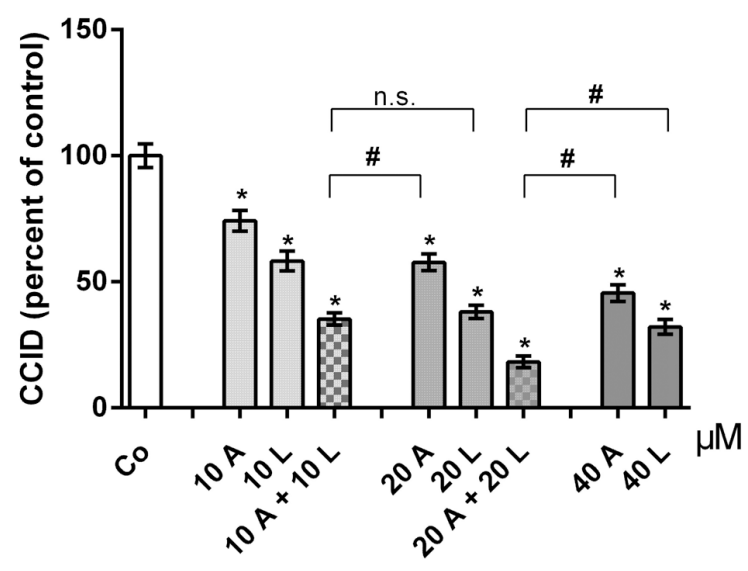

FIGURE 1 | Effects of flavonoid combinations on CCID formation. Chemical structures of (A) apigenin and (B) luteolin. (C) MDA-MB231 spheroids were placed on LEC monolayers and treated with solvent (DMSO, Co), or with 10, 20, and $40 \mu \mathrm{M}$ apigenin (A) or luteolin (L), or combinations of 10 and $20 \mu \mathrm{M} \mathrm{A}$ and L (solvent was kept constant) for $4 \mathrm{~h}$, after which CCID areas were measured using an Axiovert microscope and Zen little 2012 software. Three independent experiments with at least five replicates were analyzed. Error bars indicate means \pm SEM and asterisks and hash significances $(p<0.05 ; t$-test).

St. Louis, MO, United States). U73122 was obtained from Calbiochem (Darmstadt, Germany), BAPTA-AM was from Santa Cruz Biotechnology (Heidelberg, Germany).

siRNAs targeting human MLC2 (MYL2; SMART pool, ON-TARGET PLUS, Cat. No.: L-011087000005, siRNAs targeting human FAK (SMART pool, ON-TARGET PLUS, Cat. No.: L-003164000005) were ordered from Dharmacon (Gene Expression and Gene Editing, GE Healthcare, Lafayette, CO, United States). Non-targeting (n.t.) control siRNA (Silencer ${ }^{\circledR}$ Select Negative Control No. 1 siRNA, Cat. No.: 4390843) was purchased from Ambion (Life Technologies, Carlsbad, CA, United States). All siRNAs were re-suspended in RNAse-free water to yield a stock concentration of $20 \mu \mathrm{M}$.

\section{Cell Culture}

Human MDA-MB231 breast cancer cells from the American Type Culture Collection (ATCC, Rockville, MD, United States) were grown in MEM medium supplemented with $10 \%$ fetal calf serum (FCS), 1\% penicillin/streptomycin (PS) and 1\% non-essential amino acids (Gibco, Invitrogen, Karlsruhe, Germany). Telomerase immortalized human lymph endothelial cells (LECs) were grown in EGM2 MV (Clonetics CC-4147, Allendale, NJ, United States). The cells were kept at $37^{\circ} \mathrm{C}$ in a humidified atmosphere containing $5 \% \mathrm{CO}_{2}$. For CCID formation assays, LECs were stained with CellTracker ${ }^{\mathrm{TM}}$ green purchased from Invitrogen (Karlsruhe, Germany).

\section{Spheroid Formation}

MDA-MB231 cells (input of 6.000 cells per spheroid) were transferred to $30 \mathrm{~mL}$ serum free MEM medium containing $6 \mathrm{~mL}$ of a $1.6 \%$ methylcellulose solution $(0.3 \%$ final concentration; Cat. No.: M-512, 4000 centipoises; Sigma-Aldrich, Munich, Germany). $150 \mu \mathrm{L}$ of cell suspension were transferred to each well of a 96-well plate (Greiner Bio-one, Cellstar 650185, Kremsmünster, Austria) to allow spheroid formation within $48 \mathrm{~h}$. 


\section{CCID (Circular Chemorepellent Induced Defect) Assay}

In this assay, the sizes of the cell free areas (CCIDs) formed in the endothelial monolayer underneath the tumor spheroids, were measured. MDA-MB231 spheroids were washed in PBS and transferred to CellTracker ${ }^{\mathrm{TM}}$ (green)-stained LEC monolayers seeded into 24-well plates (Costar 3524, Sigma-Aldrich, Munich, Germany) in $1 \mathrm{~mL}$ EGM2 MV medium. After $4 \mathrm{~h}$ of incubation, the CCID areas in the LEC monolayers underneath the MDA-MB231 spheroids were photographed using an Axiovert (Zeiss, Jena, Germany) fluorescence microscope. CCID areas were calculated using the Zen Little 2012 (Zeiss, Jena, Germany). For each treatment and control the CCID size of at least 25 spheroids (unless otherwise specified) was measured.

\section{SDS Gel Electrophoresis and Western Blotting}

MDA-MB231 cells and LECs were grown in T-25 tissue culture flasks (Nunc, Roskilde, Denmark) to $80 \%$ confluence and then pre-treated with the flavonoids for $0.5,1,2$, and $4 \mathrm{~h}$. Then, cells were processed for SDS gel electrophoresis and Western blotting as described before (Nguyen et al., 2015). Chemo-luminescence was developed by Amersham ECL prime Kit (GE Healthcare, Freiburg, Germany) and detected using a Lumi-Imager F1 Workstation (Roche, Basel, Switzerland). Densitometry of the Western blots was analyzed with the Image-J software (National Institutes of Health, Bethesda, MD, United States).

\section{Ethoxyresorufin-O-Deethylase (EROD) Assay Selective for CYP1A1/A2 Activity}

MDA-MB231 cells were grown in phenol red-free DMEM/F12 medium (Gibco, Karlsruhe, Germany) containing 10\% FCS and $1 \%$ PS (Invitrogen, Karlsruhe, Germany). Before treatment, the cells were transferred to DMEM/F12 medium supplemented with $10 \%$ charcoal-stripped FCS (PAN Biotech, Aldenbach, Germany) and $1 \%$ PS. After $4 \mathrm{~h}$ of treatment with apigenin and luteolin CYP1A1 activity was measured with minor modifications as previously described (Teichmann et al., 2014). Briefly, ethoxyresorufin (final concentration $5.0 \mu \mathrm{M}$, Sigma-Aldrich, Munich, Germany) was added, $0.4 \mathrm{~mL}$ aliquots of the medium were collected after $180 \mathrm{~min}$ and the formation of resorufin was analyzed by spectro-fluorometry (PerkinElmer LS50B, Waltham, $\mathrm{MA}$, United States) at an excitation wavelength of $530 \mathrm{~nm}$ and an emission wavelength of $585 \mathrm{~nm}$.

\section{Intracellular $\mathrm{Ca}^{2+}$ Assay}

Free intracellular $\mathrm{Ca}^{2+}$ levels were measured using the FluoForte ${ }^{\mathrm{TM}}$ Calcium Assay Kit (Enzo Life Sciences, Ann Arbor, MI, United States). $8 \times 10^{3}$ LECs/well/100 $\mu$ L EGM2 medium were seeded into 96-well black-wall clear-bottom plates (Nunc, Thermo Fisher Scientific, Rochester, NY, United States) and after 24 h LECs were pre-treated with apigenin, luteolin or DMSO for $1 \mathrm{~h}$. Then, medium was removed and $100 \mu \mathrm{L}$ FluoForte ${ }^{\mathrm{TM}}$ Dye-loading (containing apigenin, luteolin, or DMSO) were added to each well. Cells were further incubated for $45 \mathrm{~min}$ at
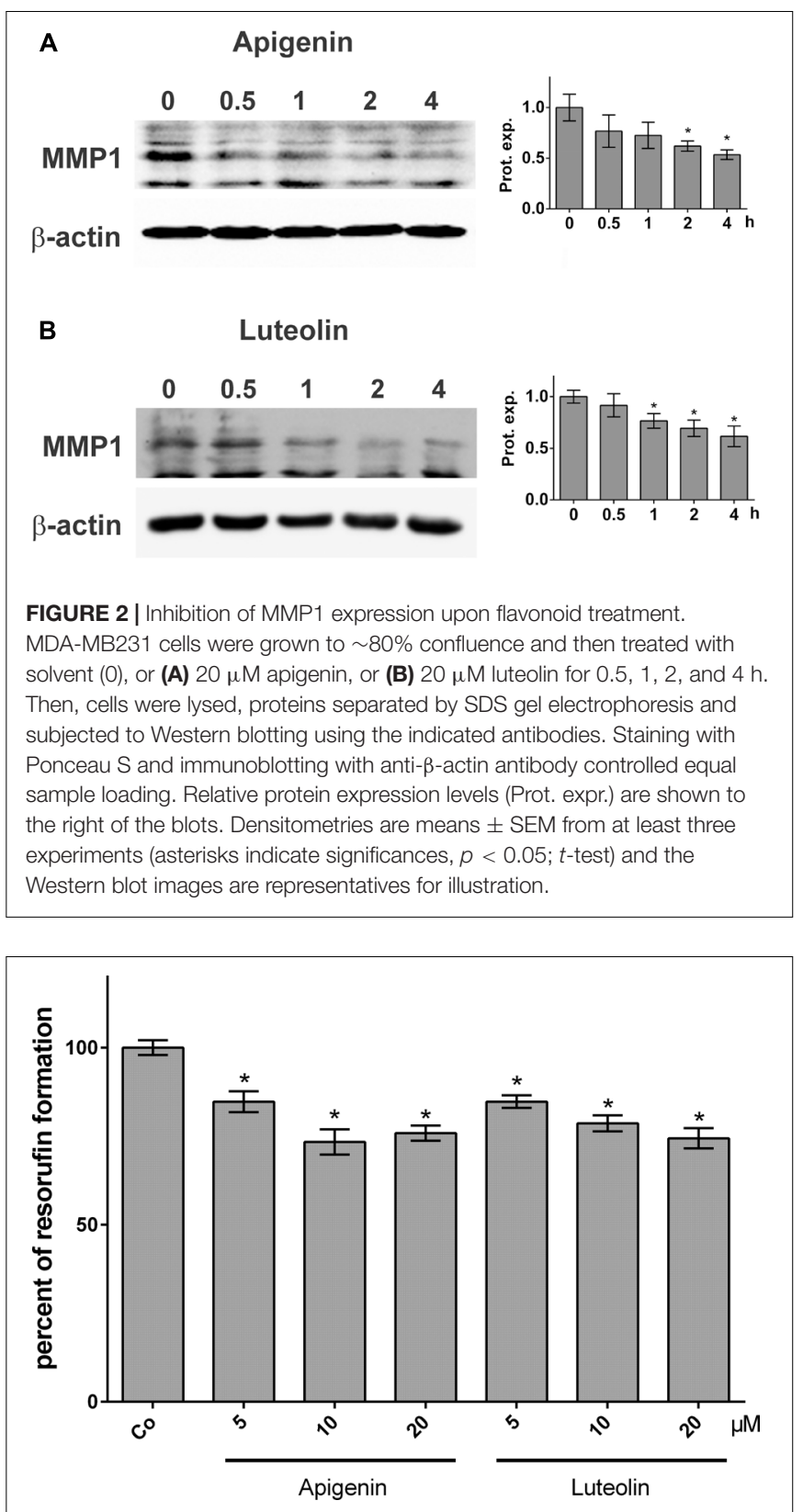

FIGURE 3 | Inhibition of CYP1A1 activity in MDA-MB231 cells by flavonoids. MDA-MB231 cells were treated with solvent (DMSO, Co), or the indicated concentrations of apigenin and luteolin. Ethoxyresorufin $(5 \mu \mathrm{M})$ was added after $4 \mathrm{~h}$ and the formation of resorufin was measured. Three independent experiments with at least three replicates were analyzed. Error bars indicate means \pm SEM and asterisks significances $\left({ }^{*} p<0.05\right.$; ANOVA together with Tukey's post-test).

$37^{\circ} \mathrm{C}$ followed by $15 \mathrm{~min}$ at room temperature. Then, cells were stimulated with $1 \mu \mathrm{M} \mathrm{12(S)-HETE} \mathrm{for} 5 \mathrm{~min}$, and fluorescence was measured with a fluorescence plate reader at $490 / 525 \mathrm{~nm}$.

\section{Transfection of LEC Monolayer}

Lymph endothelial cells were seeded in 24-well plates $(1 \mathrm{~mL} /$ well) and grown in EGM2 medium. Transfections were performed 

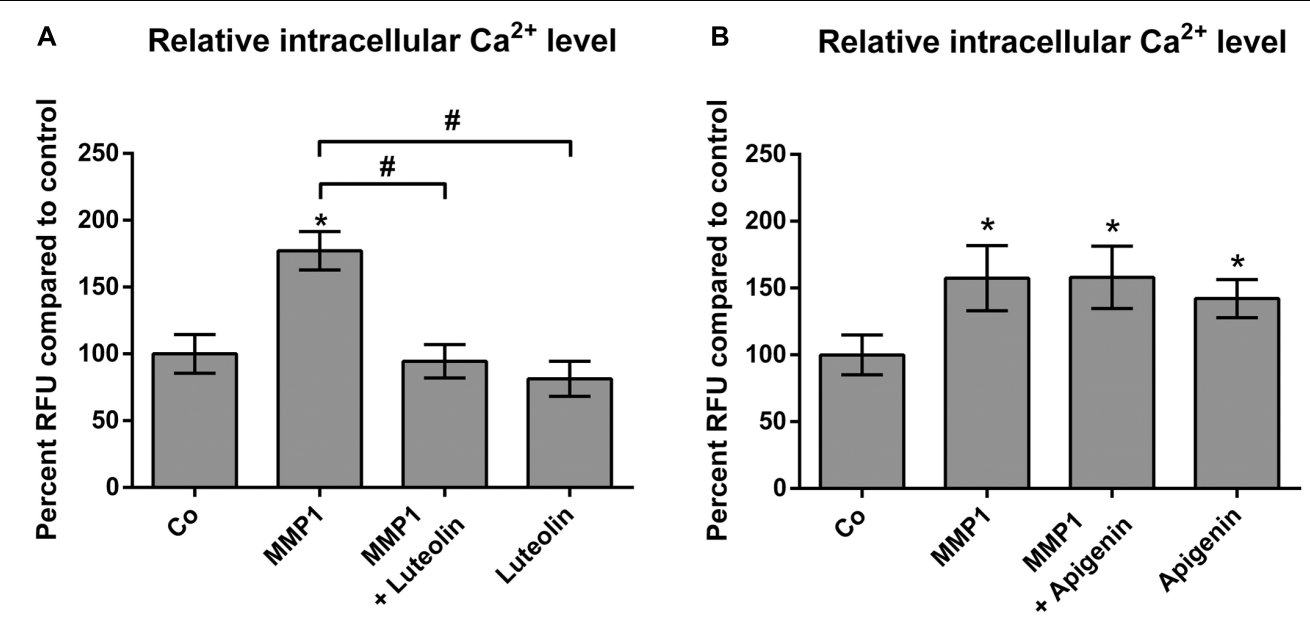

FIGURE 4 | Modulation of MMP1-induced $\mathrm{Ca}^{2}+$ release by flavonoids in LECs. LECs $\left(8 \times 10^{3}\right.$ cells/well) were pre-treated with solvent (DMSO, Co), or (A) $20 \mu \mathrm{M}$ luteolin, or (B) $20 \mu \mathrm{M}$ apigenin and then charged with FluoForte Dye-loading for $45 \mathrm{~min}$ at $37^{\circ} \mathrm{C}$ and 15 min at room temperature when cells were stimulated with $100 \mathrm{ng} / \mathrm{mL}$ activated recombinant MMP1 for $5 \mathrm{~min}$. Intracellular free calcium was measured with a fluorescence plate reader at $490 / 525 \mathrm{~nm}$. Three independent experiments with at least two replicates were analyzed. Error bars indicate means \pm SEM, and asterisks and hash significances ( $p<0.05$; $t$-test).

at a confluence of $70-80 \%$. $0.75 \mu \mathrm{g}$ siRNA and $6 \mu \mathrm{L}$ HiPerFect Transfection Reagent (Cat. No.: 301705; Qiagen, Hilden, Germany) were mixed in $100 \mu \mathrm{L}$ serum-free medium and incubated for $30 \mathrm{~min}$ at room temperature to allow the formation of transfection complexes. Cell culture medium was discarded and $500 \mu \mathrm{L}$ of fresh EGM2 medium were added into each well. Then, the transfection complexes were added drop-wise to the cells (to a final siRNA concentration of $100 \mathrm{nM}$ ) and incubated for $24 \mathrm{~h}$ at $37^{\circ} \mathrm{C}$. After $24 \mathrm{~h}$, the medium was replaced and cells were incubated for another $24 \mathrm{~h}$ to recover. The LEC monolayers were used for CCID assays or isolated RNA for qPCR.

\section{Statistical Analysis}

For statistical analyses Excel 2013 software and Prism 6 software packages (GraphPad, San Diego, CA, United States) were used. The values were expressed as mean \pm SEM, and the Student's $t$-test and ANOVA with Tukey's post-test was used to compare differences between control samples and treatment groups as well as differences among treatment groups. The statistical significance level was set to $p<0.05$.

\section{RESULTS}

\section{Apigenin/Luteolin Inhibit CCID Formation Induced by MDA-MB231 Spheroids}

Breast cancer cells have to intravasate the lymphatic barrier to colonize lymph nodes, and the CCID in vitro assay realistically resembles the intravasation of tumor spheroids through the lymphatic vasculature (Kerjaschki et al., 2011). Treatment of the three-dimensional MDA-MB231/LEC model with apigenin (Figure 1A) and luteolin (Figure 1B) dose dependently inhibited CCID formation in the LEC monolayer, with luteolin showing a stronger effect than apigenin. Simultaneous treatment with
$20 \mu \mathrm{M}$ luteolin and $20 \mu \mathrm{M}$ apigenin synergized and inhibited CCID formation significantly stronger than $40 \mu \mathrm{M}$ luteolin or $40 \mu \mathrm{M}$ apigenin, respectively, thus suggesting that luteolin and apigenin interfered with distinct pro-intravasative mechanisms (Figure 1C).

\section{Apigenin/Luteolin Inhibit MMP1 Expression and CYP1A1 Activity in MDA-MB231 Cells}

MDA-MB231 cell spheroids express MMP1, which is one mechanism causing CCIDs in the adjacent LEC monolayer (Nguyen et al., 2015). Thus, the expression of MMP1 was investigated after treatment of MDA-MB231 cells with apigenin and luteolin. $20 \mu \mathrm{M}$ apigenin and $20 \mu \mathrm{M}$ luteolin caused a significant and time-dependent down-regulation of MMP1 protein (Figures 2A,B).

Another mechanism of breast cancer emboli to cross the endothelial barrier is the secretion of 12 (S)-HETE which, in MDA-MB231 cells, is produced by CYP1A1 (Nguyen et al., 2016a). Hence, the activity of CYP1A1 in MDA-MB231 cells was analyzed by EROD assay after treatment with increasing concentrations of apigenin and luteolin. 5-20 $\mu \mathrm{M}$ apigenin and luteolin inhibited CYP1A1 activity significantly within $4 \mathrm{~h}$ (Figure 3).

The results proved that apigenin and luteolin inhibited MMP1 expression and CYP1A1 activity, which trigger the retraction of the adjacent LEC barrier thereby enabling MDA-MB231 tumor spheroid intravasation.

\section{Influence of Apigenin and Luteolin on Intracellular $\mathrm{Ca}^{2+}$ Release in LEC}

The intravasation of breast cancer cells relies on an interplay between cancer emboli and the LEC barrier (Vonach et al., 2011; Viola et al., 2013). Therefore, it was investigated whether apigenin 
A

Treatment of the MDA-MB231/LEC model with
BAPTA-AM and apigenin

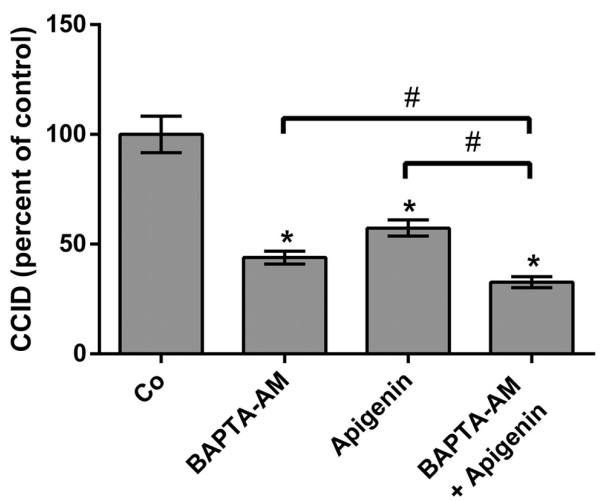

C

Treatment of the MDA-MB231/LEC model with BAPTA-AM and luteolin

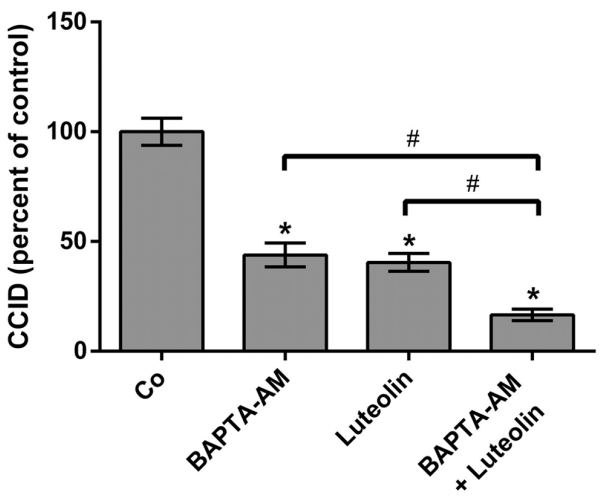

B

Treatment of the MDA-MB231/LEC model with
U73122 and apigenin

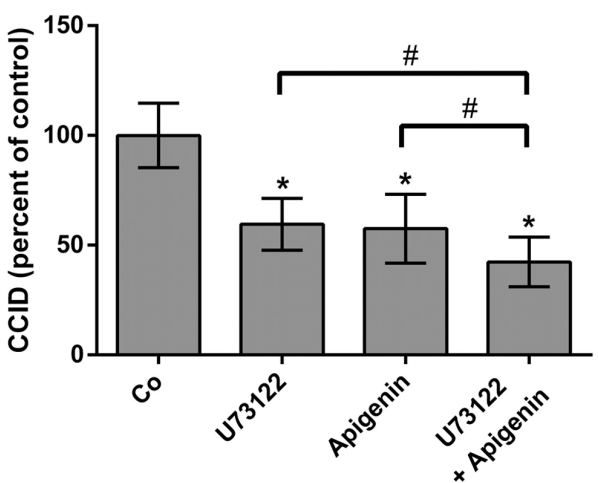

D Treatment of the MDA-MB231/LEC model with U73122 and luteolin

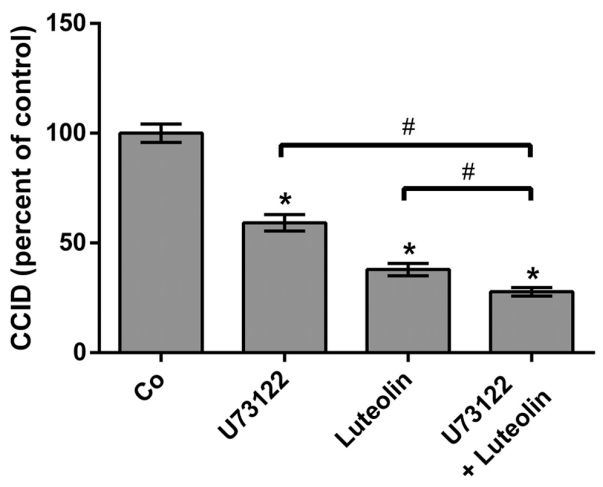

FIGURE 5 | Analysis of drug combinations on CCID formation. MDA-MB231 spheroids were placed on LEC monolayers and treated with solvent (DMSO, Co), or (A,B) $20 \mu \mathrm{M}$ apigenin, or (C,D) $20 \mu \mathrm{M}$ luteolin, alone, or together with (A,C) $5 \mu \mathrm{M}$ BAPTA-AM, or together with (B,D) $2.5 \mu \mathrm{M}$ U73122 for $4 \mathrm{~h}$, after which CCID areas were measured using an Axiovert microscope and Zen little 2012 software. Three independent experiments with at least five replicates were analyzed. Error bars indicate means \pm SEM and asterisks and hash significances $\left({ }^{*} p<0.05 ; t\right.$-test).

or luteolin would also inhibit the pro-intravasative response of LECs.

The release of $\mathrm{Ca}^{2+}$ from intracellular stores plays a central role in MMP1- and 12(S)-HETE-induced CCID formation (Nguyen et al., 2016b; Stadler et al., 2017). Hence, it was tested whether apigenin and luteolin affected intracellular $\mathrm{Ca}^{2+}$ release. Luteolin prevented MMP1-induced $\mathrm{Ca}^{2+}$ increase (Figure 4A), which is consistent with previous reports (Jiang et al., 2005). In contrast, apigenin did not reduce MMP1-induced $\mathrm{Ca}^{2+}$ levels in LECs, but in contrast increased $\mathrm{Ca}^{2+}$ release (Figure 4B). This is in agreement with data that apigenin activates potassium channels leading to their hyper-polarization and causing the release of $\mathrm{Ca}^{2+}$ (Erdogan et al., 2007). Accordingly, treating the MDA-MB231/LEC model with apigenin and BAPTA-AM (intracellular $\mathrm{Ca}^{2+}$ inhibitor) caused a significantly stronger inhibition of CCID formation than apigenin alone, or BAPTA-AM alone (Figure $\mathbf{5 A}$ ). $\mathrm{Ca}^{2+}$ release is dependent on PLC $\beta$ activity and, therefore, also the co-treatment with apigenin and U73122 (PLC inhibitor) attenuated CCID formation significantly stronger than the treatment with just apigenin or U73122 (Figure 5B). Luteolin ameliorated the CCID-inhibitory effect of BAPTA-AM (Figure 5C) or U73122 (Figure 5D) even more efficiently than apigenin. Overall, these data support the notion that an additional intravasative mechanism, which was independent of $\mathrm{Ca}^{2+}$ signaling, must have been inhibited by apigenin and luteolin as well.

\section{Luteolin/Apigenin Inhibit}

\section{Phosphorylation of Tyr397-FAK in LEC}

The FAK controls cell-matrix interactions and mobility (Schwock et al., 2010) as observed in CCID formation (Nguyen et al., 2015). Recombinant MMP1 induced the phosphorylation of FAK at Tyr397 indicative for its activation. Pre-treatment 


\section{A}

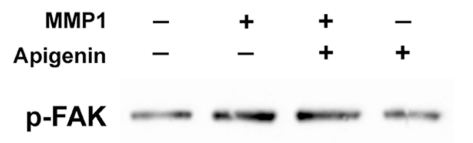

FAK

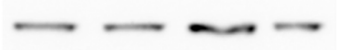

$\beta$-actin

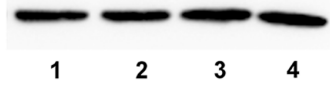

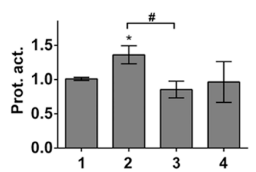

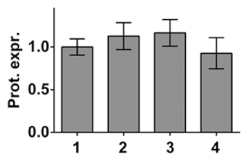

B
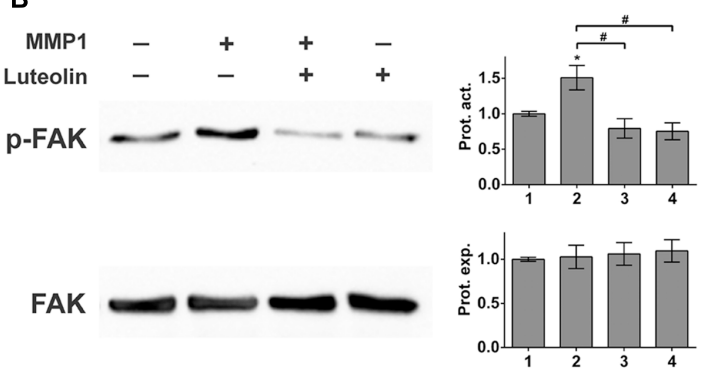

$\beta$-actin

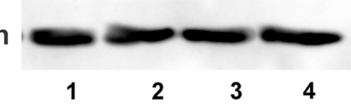

FIGURE 6 | MMP1 activates focal adhesion kinase (FAK) in LECs. LECs were grown to 70-80\% confluence and then pre-treated with solvent (DMSO), or (A) $20 \mu \mathrm{M}$ apigenin, or (B) $20 \mu \mathrm{M}$ luteolin and then stimulated with $100 \mathrm{ng} / \mathrm{mL}$ activated recombinant MMP1 for $4 \mathrm{~h}$. Cells were lysed, proteins were separated by SDS gel electrophoresis and analyzed by Western blotting using the indicated antibodies. Equal sample loading was controlled by Ponceau $S$ staining and $\beta$-actin immunoblotting. The relative protein expression (Prot. expr.) was quantified by densitometry facilitating the comparison with $\beta$-actin control, which was set to a value of "1." The calculated FAK protein expression levels are shown in the bar graphs next to the FAK Western blots. The relative phosphorylation of FAK ( $p$-FAK; corresponding to FAK activity) was quantified by densitometry facilitating the comparison with FAK protein expression, which was set to a value of "1." The calculated FAK protein activity levels (Prot. Act.) are shown in the bar graphs next to the p-FAK Western blots. The numbers below the bar graphs refer to the respective treatment conditions indicated in the blot lanes. Densitometries are means \pm SEM from at least three experiments (asterisks indicate significances, $p<0.05$; $t$-test) and the Western blot images are representatives for illustration. Hashes (\#; rhomboids) indicate significance.
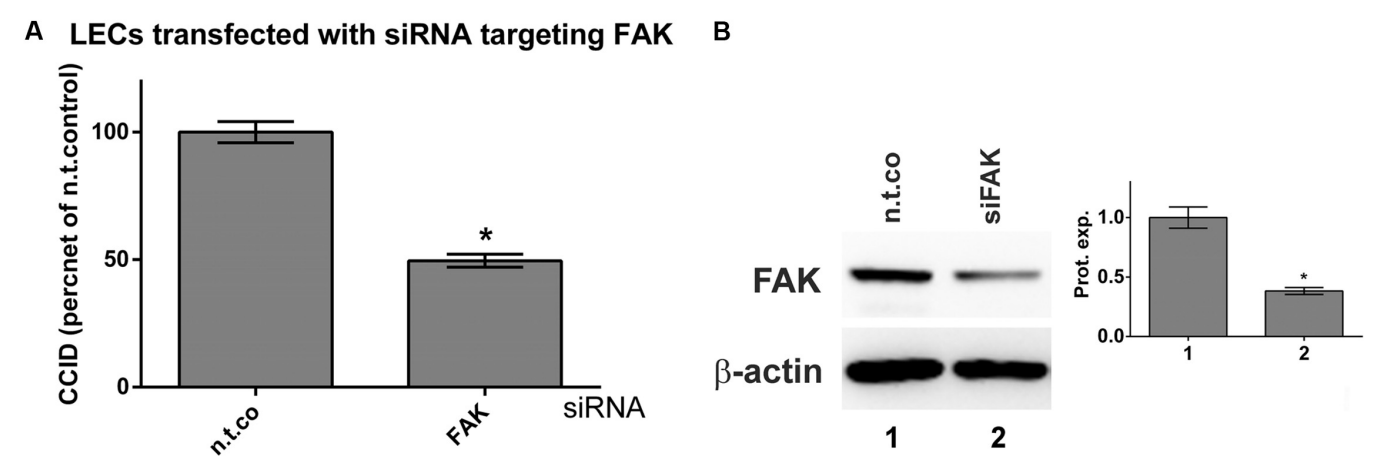

FIGURE 7 | Inhibition of focal adhesion kinase (FAK) expression in LECs by specific siRNA. LECs were transiently transfected with either non-targeting siRNA (n.t.co) or siRNA inhibiting the expression of FAK. (A) MDA-MB231 spheroids were placed on confluent LEC monolayers and co-incubated for $4 \mathrm{~h}$ when the areas of CCIDs were analyzed using an Axiovert microscope and Zen Little 2012 software. Three independent experiments with at least five replicates were analyzed. (B) After $24 \mathrm{~h}$ cells were lysed, total protein was isolated, separated by SDS-PAGE and transferred to PVDF membranes for Western blotting using FAK antibody. $\beta$-Actin was used to control equal sample loading. Relative protein expression levels (Prot. expr.) are shown to the right of the blots and the numbers below the bar graphs refer to the respective treatment conditions shown below the lanes. Densitometries are means $\pm \mathrm{SEM}$ from at least three experiments (asterisks indicate significances, $p<0.05$; $t$-test) and the Western blot images are representatives for illustration.

with apigenin or luteolin prevented MMP1-induced, but not constitutive FAK phosphorylation (Figures 6A,B). The inhibition of Tyr397-FAK phosphorylation by apigenin did not correlate with the inhibition of $\mathrm{Ca}^{2+}$ release. Therefore, the relevance of FAK for CCID formation was studied by siRNA-mediated knock-down of FAK (siFAK). In fact, siFAK transfection of LECs suppressed MDA-MB231-induced CCID formation by $50 \%$ (Figure 7A). The knock-down of FAK was confirmed by Western blotting (Figure 7B). Hence, FAK significantly contributed to intravasation in vitro and apigenin and luteolin inhibited this mechanism.

Earlier work demonstrated that CCID formation through MLC2 depends on intracellular $\mathrm{Ca}^{2+}$ release (Nguyen et al.,
2015). Our results show that FAK-dependent CCID formation did not correlate with intracellular $\mathrm{Ca}^{2+}$ levels. Although both pathways were induced by MMP1, they, obviously, are independent of each other. Thus, we hypothesized that simultaneous inhibition of MLC2 $\left(\mathrm{Ca}^{2+}\right.$-dependent $)$ and FAK $\left(\mathrm{Ca}^{2+}\right.$-independent $)$ by respective siRNAs, should bring about a greater reduction in CCID formation than inhibition of either FAK or MLC2 alone, which was actually confirmed (Figure 8). This supports former data (Figure 1C) showing that luteolin (inhibiting FAK and $\mathrm{Ca}^{2+}$ release) and apigenin (inhibiting FAK but not $\mathrm{Ca}^{2+}$ release) synergize in CCID attenuation via distinct signaling pathways. 


\section{LECs transfected with siRNA targeting FAK and MLC2}

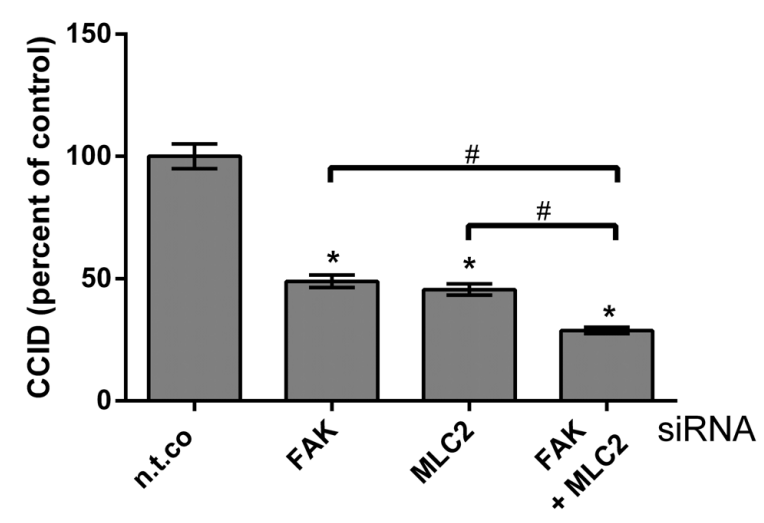

FIGURE 8 | Inhibition of focal adhesion kinase (FAK) and myosin light chain 2 (MLC2) protein expression in LECs by specific siRNAs. LECs were transiently transfected with either non-targeting siRNA (n.t.co), or siRNAs inhibiting the expression of FAK and MLC2. Then, MDA-MB231 spheroids were placed on confluent LEC monolayers and co-incubated for $4 \mathrm{~h}$, after which the areas of CCIDs were analyzed using an Axiovert microscope and Zen Little 2012 software. Three independent experiments with at least five replicates were analyzed. Error bars indicate means \pm SEM, asterisks and hash significances $(p<0.05 ;$ t-test).

\section{DISCUSSION}

We show for the first time that luteolin and apigenin attenuate the intravasation of breast cancer cells in vitro. At the tested concentrations, luteolin and apigenin inhibited CYP1A1 activity in MDA-MB231 cells. CYP1A1 synthesizes the pro-metastatic arachidonic acid metabolite 12(S)-HETE and is induced, e.g., by the activated aryl hydrocarbon receptor, the expression of which is high in many cancer entities (Murray et al., 2014) and also in MDA-MB231 cells (Nguyen et al., 2016a). In HepG2 cells with a luciferase reporter fused to the CYP1A1-regulator region, $5 \mu \mathrm{M}$ apigenin increased reporter gene expression by threefold. In contrast, the higher concentration of $20 \mu \mathrm{M}$ apigenin inhibited the expression by 50\% (Allen et al., 2001). In cell-free assays luteolin inhibited CYP1A1 more potently than apigenin, whereas CYP1A2 was inhibited more efficiently by apigenin (Kim et al., 2005). CYP1A2 mediates the formation of flavonoid metabolites with different properties to the genuin compounds. The comparability of flavonoid effects is rather difficult among different cell lines, which depend on the expression and activity profiles of the various CYP isoforms converting these flavonoids to other (more or less active) products (Androutsopoulos et al., 2009). Based on the very different individual expression levels of CYP1A2 in humans, Breinholt et al. (2002) conclude that this may result in different individual sensitivity.

Apigenin and luteolin inhibited also MMP1 expression in MDA-MB231 cells. MMP1 expression is induced by NF-кB (Lee et al., 2011), which is activated not only in inflamed- but also in cancerous tissue (Karin and Greten, 2005; Karin, 2006). Recently, we provided evidence that specific inhibition of
NF-кB (by siRELA, siNFKB1, siNEMO) down-regulated MMP1 expression and attenuated CCID formation (Nguyen et al., 2015). Flavones such as apigenin and luteolin inhibited NF- $\kappa$ B activity and consequently the expression of its target MMP9 (Amrutha et al., 2014). Hence, the inhibition of NF- $\mathrm{B}$ by apigenin and luteolin may have been the reason for suppressed MMP1 levels in MDA-MB231 cells.

As shown here, recombinant MMP1 significantly induced the phosphorylation of FAK at Tyr397 in LECs. FAK activity contributes to cancer cell migration by establishing loose cell-matrix interactions necessary for rapid cell movement (Desai et al., 2009; Schwock et al., 2010), as described in CCID formation (Kerjaschki et al., 2011). In our experiments suppression of FAK significantly inhibited CCID formation. The activation of FAK (through phosphorylation of Tyr397) is mediated through Kv2.1 channels (Wei et al., 2008). Since FAK as well as potassium channel activity contribute to LEC retraction and CCID formation (Nguyen et al., 2017), the reduction of Tyr397-FAK phosphorylation by apigenin may have been due to the inhibition of potassium channels. This was supported by reports demonstrating that trimethyl-apigenin interfered with cardiac potassium currents (Liu et al., 2012) and the inhibition of potassium channel activity by the flavonoids acacetin, scutellarin, genistein, and naringenin (Teisseyre and Michalak, 2005; Zhu et al., 2008; Wu et al., 2011; Gasiorowska et al., 2012). However, quite to the contrary, apigenin and luteolin exhibited vasodilatory effects, which are discussed to be due to activation (rather than inactivation) of potassium channels (Calderone et al., 2004; Jiang et al., 2005). A more recent research concluded that the vasodilatory properties of apigenin and luteolin were independent of potassium channel inhibition, but due to extracellular calcium influx (Roberts et al., 2013). Therefore, the mechanism by which apigenin and luteolin inhibit FAK phosphorylation remains to be established.

MMP1 also activates the mobility protein MLC2 in LECs, which contributes to CCID formation as well (Nguyen et al., 2015, 2016c). MMP1 binds to PAR1, activates PLC $\beta$, triggers $\mathrm{Ca}^{2+}$ release and activates the $\mathrm{Ca}^{2+}$-calmodulin kinase MYLK, which phosphorylates MLC2. MMP1 was also shown to cause migration by binding to PAR1 in breast cancer cells (Boire et al., 2005) and blood endothelial cells (Juncker-Jensen et al., 2013). Whereas MMP1-induced MLC2 activation depends on $\mathrm{Ca}^{2+}$ release, FAK activation was not found to correlate with intracellular $\mathrm{Ca}^{2+}$ levels. This implicates that the pathway activating FAK represents a pro-intravasative mechanism independent of the one activating MLC2. Therefore, the inhibition both of FAK (either by siFAK or apigenin) and of MLC2 (by siMLC2, or BAPTA-AM, or U73122) reduced CCID formation in LEC monolayers to a greater extent than the inhibition of just one pathway.

Summing up, luteolin and apigenin inhibited pro-intravasative mechanisms in MDA-MB231 breast cancer cells at the levels of CYP1A1 activity and MMP1 expression. In LECs, apigenin and luteolin inhibited MMP1-induced, aberrant FAK activity but not constitutive, normal FAK phosphorylation. Only luteolin inhibited $\mathrm{Ca}^{2+}$ signaling in LEC, which contributed 
to CCID formation (Nguyen et al., 2016b). This may explain why luteolin affected CCID formation more potently than apigenin as well as the synergism between apigenin and luteolin.

The results implicate that luteolin and apigenin maintained the resilience of the endothelial barrier whilst attacking cancer cells and additionally, inhibited the malignant armamentarium of the tumor. Luteolin and apigenin exerted their effects at low $\mu \mathrm{M}$ concentrations which usually cannot be reached by daily dietary intake (Vogiatzoglou et al., 2015). Nevertheless, the daily intake of particular flavonoid subclasses (flavonols, flavan-3-ols, anthocyanidins) significantly correlates inversely with the risk of colorectal cancer (Woo and Kim, 2013). However, no other flavonoid subclasses or total flavonoids are associated with a lower risk of breast cancer in post-menopausal women (Hui et al., 2013). Intake of highly enriched apigenin and luteolin formulations achieved flavonoid concentrations in blood plasma which are comparable to those described herein in vitro. In detail, a single oral dose of apigenin delivered via a carbon nanopowder solid dispersion carrier $(60 \mathrm{mg} / \mathrm{kg})$ to rats resulted in peak plasma concentrations of up to $3.2 \mu \mathrm{g} / \mathrm{mL}$ which corresponds to $11.8 \mu \mathrm{M}$ (Ding et al., 2014). Similarly, a single oral dose luteolin in a peanut hull extract $(14.3 \mathrm{mg} / \mathrm{kg})$ to rats resulted in peak plasma concentrations of up to $8.3 \mu \mathrm{g} / \mathrm{mL}(29.1 \mu \mathrm{M})$ (Zhou et al., 2008). The evaluation as to whether these concentrations are free of negative side effects throughout long term treatment requires controlled phase I studies.

\section{REFERENCES}

Akram, M. (2013). Minireview on Achillea millefolium Linn. J. Membr. Biol. 246, 661-663. doi: 10.1007/s00232-013-9588-x

Allen, S. W., Mueller, L., Williams, S. N., Quattrochi, L. C., and Raucy, J. (2001). The use of a high-volume screening procedure to assess the effects of dietary flavonoids on human CYP1A1 expression. Drug Metab. Dispos. 29, 1074-1079.

Amrutha, K., Nanjan, P., Shaji, S. K., Sunilkumar, D., Subhalakshmi, K., Rajakrishna, L., et al. (2014). Discovery of lesser known flavones as inhibitors of NF- $\kappa \mathrm{B}$ signaling in MDA-MB-231 breast cancer cells-A SAR study. Bioorg. Med. Chem. Lett. 24, 4735-4742. doi: 10.1016/j.bmcl.2014.07.093

Androutsopoulos, V. P., Ruparelia, K., Arroo, R. R., Tsatsakis, A. M., and Spandidos, D. A. (2009). CYP1-mediated antiproliferative activity of dietary flavonoids in MDA-MB-468 breast cancer cells. Toxicology 264, 162-170. doi: 10.1016/j.tox.2009.07.023

Attoub, S., Hassan, A. H., Vanhoecke, B., Iratni, R., Takahashi, T., Gaben, A. M., et al. (2011). Inhibition of cell survival, invasion, tumor growth and histone deacetylase activity by the dietary flavonoid luteolin in human epithelioid cancer cells. Eur. J. Pharmacol. 651, 18-25. doi: 10.1016/j.ejphar.2010. 10.063

Benedek, B., Gjoncaj, N., Saukel, J., and Kopp, B. (2007). Distribution of phenolic compounds in Middleeuropean taxa of the Achillea millefolium L. aggregate. Chem. Biodivers. 4, 849-857. doi: 10.1002/cbdv.200790072

Benetis, R., Radusiene, J., and Janulis, V. (2008). Variability of phenolic compounds in flowers of Achillea millefolium wild populations in Lithuania. Medicina 44, 775-781.

Boire, A., Covic, L., Agarwal, A., Jacques, S., Sherifi, S., and Kuliopulos, A. (2005). PAR 1 is a matrix metalloprotease- 1 receptor that promotes invasion and tumorigenesis of breast cancer cells. Cell 120, 303-313. doi: 10.1016/j.cell.2004. 12.018

Breinholt, V. M., Offord, E. A., Brouwer, C., Nielsen, S. E., Brøsen, K., and Friedberg, T. (2002). In vitro investigation of cytochrome P450-mediated metabolism of dietary flavonoids. Food Chem. Toxicol. 40, 609-616. doi: 10.1016/S0278-6915(01)00125-9

\section{AUTHOR CONTRIBUTIONS}

$\mathrm{JlH}, \mathrm{AF}$, and $\mathrm{DM}$ performed the experiments. $\mathrm{CN}, \mathrm{NH}$, and SK analyzed the data. JqH, SG, PB, and WJ were involved in experiment planning and supervision. AÖ, LK, and GK supervised experimental work, and compiled and interpreted the data. LK and GK wrote the manuscript.

\section{FUNDING}

$\mathrm{JlH}$ was supported by a State Scholarship Fund of China Scholarship Council, the National Natural Science Foundation of China (No. 81202853), the Natural Science Foundation of Jiangsu Province (No. BK2012444), and Jiangsu Planned Projects for Postdoctoral Research Funds, AF by a DIKTI-OeAD fellowship, and $\mathrm{CN}$ by a technology grant (TSA Doktorat) financed by the Austrian Federal Ministry of Science and Research (BMFW) within the framework of ASEAUNINET.

\section{ACKNOWLEDGMENTS}

We wish to thank Toni Jäger for preparing the figures and Gertrud Krainz for improvements in grammar and style.

Calderone, V., Chericoni, S., Martinelli, C., Testai, L., Nardi, A., Morelli, I., et al. (2004). Vasorelaxing effects of flavonoids: investigation on the possible involvement of potassium channels. Naunyn Schmiedebergs Arch. Pharmacol. 370, 290-298.

Desai, L. P., White, S. R., and Waters, C. M. (2009). Mechanical stretch decreases FAK phosphorylation and reduces cell migration through loss of JIP3-induced JNK phosphorylation in airway epithelial cells. Am. J. Physiol. Lung Cell. Mol. Physiol. 297, 520-529. doi: 10.1152/ajplung.00076.2009

Ding, S. M., Zhang, Z. H., Song, J., Cheng, X. D., Jiang, J., and Jia, X. B. (2014). Enhanced bioavailability of apigenin via preparation of a carbon nanopowder solid dispersion. Int. J. Nanomed. 9, 2327-2333. doi: 10.2147/IJN. S60938

Dioscurides, P. (1st century A.D.). De Materia Medica, Copy from the 6th Century, Konstantinopel; Since 16th Century (by Emperor Ferdinand I) at the Department of Manuscripts and Rare Books Collection of the Austrian National Library. Vienna: Codex Vindobonensis med. Gr. 1.

Erdogan, A., Most, A. K., Wienecke, B., Fehsecke, A., Leckband, C., Voss, R., et al. (2007). Apigenin-induced nitric oxide production involves calcium-activated potassium channels and is responsible for antiangiogenic effects. J. Thromb. Haemost. 5, 1774-1781. doi: 10.1111/j.1538-7836.2007.02615.x

Galindez, J. D., Lanza, A. M. D., and Matellano, L. F. (2002). Biologically active substances from the genus Scrophularia. Pharm. Biol. 40, 45-99. doi: 10.1076/ phbi.40.1.45.5864

Gasiorowska, J., Teisseyre, A., Uryga, A., and Michalak, K. (2012). The influence of 8-prenylnaringenin on the activity of voltage-gated Kv1.3 potassium channels in human Jurkat T cells. Cell. Mol. Biol. Lett. 17, 559-570. doi: 10.2478/s11658012-0029-0

Giessrigl, B., Yazici, G., Teichmann, M., Kopf, S., Ghassemi, S., Atanasov, A. G., et al. (2012). Effects of Scrophularia extracts on tumor cell proliferation, death and intravasation through lymphoendothelial cell barriers. Int. J. Oncol. 40, 2063-2074. doi: 10.3892/ijo.2012.1388

Hui, C., Qi, X., Qianyong, Z., Xiaoli, P., Jundong, Z., and Mantian, M. (2013). Flavonoids, flavonoid subclasses and breast cancer risk: a meta-analysis of epidemiologic studies. PLoS One 8:e54318. doi: 10.1371/journal.pone. 0054318 
Jiang, H., Xia, Q., Wang, X., Song, J., and Bruce, I. C. (2005). Luteolin induces vasorelaxion in rat thoracic aorta via calcium and potassium channels. Pharmazie 60, 444-447.

Juncker-Jensen, A., Deryugina, E. I., Rimann, I., Zajac, E., Kupriyanova, T. A., Engelholm, L. H., et al. (2013). Tumor MMP-1 activates endothelial PAR1 to facilitate vascular intravasation and metastatic dissemination. Cancer Res. 73, 4196-4211. doi: 10.1158/0008-5472.CAN-12-4495

Karin, M. (2006). Nuclear factor-kappaB in cancer development and progression. Nature 441, 431-436. doi: 10.1038/nature04870

Karin, M., and Greten, F. R. (2005). NF-kappaB: linking inflammation and immunity to cancer development and progression. Nat. Rev. Immunol. 5, 749-759. doi: 10.1038/nri1703

Kerjaschki, D., Bago-Horvath, Z., Rudas, M., Sexl, V., Schneckenleithner, C., Wolbank, S., et al. (2011). Lipoxygenase mediates invasion of intrametastatic lymphatic vessels and propagates lymph node metastasis of human mammary carcinoma xenografts in mouse. J. Clin. Invest. 121, 2000-2012. doi: 10.1172/ JCI44751

Kim, H. J., Lee, S. B., Park, S. K., Kim, H. M., Park, Y. I., and Dong, M. S. (2005). Effects of hydroxyl group numbers on the B-ring of 5,7-dihydroxyflavones on the differential inhibition of human CYP 1A and CYP1B1 enzymes. Arch. Pharm. Res. 28, 1114-1121. doi: 10.1007/BF02972971

Lee, S. T., Li, Z., Wu, Z., Aau, M., Guan, P., Karuturi, R. K., et al. (2011). Contextspecific regulation of NF- $\kappa \mathrm{B}$ target gene expression by EZH2 in breast cancers. Mol. Cell 43, 798-810. doi: 10.1016/j.molcel.2011.08.011

Lewenhofer, V., Schweighofer, L., Ledermüller, T., Eichsteininger, J., Kählig, H., Zehl, M., et al. (2018). Chemical composition of Scrophularia lucida and the effects on tumor invasiveness in vitro. Front. Pharmacol.

Lin, D., Kuang, G., Wan, J., Zhang, X., Li, H., Gong, X., et al. (2017). Luteolin suppresses the metastasis of triple-negative breast cancer by reversing epithelial-to-mesenchymal transition via downregulation of $\beta$-catenin expression. Oncol. Rep. 37, 895-902. doi: 10.3892/or.2016.5311

Lindenmeyer, F., Li, H., Menashi, S., Soria, C., and Lu, H. (2001). Apigenin acts on the tumor cell invasion process and regulates protease production. Nutr. Cancer 39, 139-147. doi: 10.1207/S15327914nc391_19

Liu, Y., Xu, X. H., Liu, Z., Du, X. L., Chen, K. H., Xin, X., et al. (2012). Effects of the natural flavone trimethylapigenin on cardiac potassium currents. Biochem. Pharmacol. 84, 498-506. doi: 10.1016/j.bcp.2012.05.002

Murray, A. T. (1924). The Iliad, English trans. Homer Ph.D. in two volumes. Cambridge, MA: Harvard University Press.

Murray, I. A., Patterson, A. D., and Perdew, G. H. (2014). Aryl hydrocarbon receptor ligands in cancer: friend and foe. Nat. Rev. Cancer 14, 801-814. doi: $10.1038 / \mathrm{nrc} 3846$

Nguyen, C. H., Brenner, S., Huttary, N., Atanasov, A. G., Dirsch, V. M., Chatuphonprasert, W., et al. (2016a). AHR/CYP1A1 interplay triggers lymphatic barrier breaching in breast cancer spheroids by inducing 12(S)-HETE synthesis. Hum. Mol. Genet. 25, 5006-5016. doi: $10.1093 / \mathrm{hmg} / \mathrm{ddw} 329$

Nguyen, C. H., Brenner, S., Huttary, N., Li, Y., Atanasov, A. G., Dirsch, V. M., et al. (2016b). 12(S)-HETE increases intracellular $\mathrm{Ca}^{2+}$ in lymph-endothelial cells disrupting their barrier function in vitro; stabilization by clinical drugs impairing calcium supply. Cancer Lett. 380, 174-183. doi: 10.1016/j.canlet.2016. 06.022

Nguyen, C. H., Huttary, N., Atanasov, A. G., Chatuphonprasert, W., Brenner, S., Fristiohady, A., et al. (2017). Fenofibrate inhibits tumor intravasation by several independent mechanisms in a 3-dimensional co-culture model. Int. J. Oncol. 50, 1879-1888. doi: 10.3892/ijo.2017.3956

Nguyen, C. H., Senfter, D., Basilio, J., Holzner, S., Stadler, S., Krieger, S., et al. (2015). NF-кB contributes to MMP1 expression in breast cancer spheroids causing paracrine PAR1 activation and disintegrations in the lymph endothelial barrier in vitro. Oncotarget 6, 39262-39275. doi: 10.18632/oncotarget. 5741

Nguyen, C. H., Stadler, S., Brenner, S., Huttary, N., Krieger, S., Jäger, W., et al. (2016c). Cancer cell-derived 12(S)-HETE signals via 12-HETE receptor, RHO, ROCK and MLC2 to induce lymph endothelial barrier breaching. Br. J. Cancer 115, 364-370. doi: 10.1038/bjc.2016.201

Qin, Y., Zhao, D., Zhou, H. G., Wang, X. H., Zhong, W. L., Chen, S., et al. (2016). Apigenin inhibits NF- $\mathrm{B}$ and snail signaling, EMT and metastasis in human hepatocellular carcinoma. Oncotarget 7, 41421-41431. doi: 10.18632/ oncotarget.9404
Roberts, R. E., Allen, S., Chang, A. P., Henderson, H., Hobson, G. C., Karania, B., et al. (2013). Distinct mechanisms of relaxation to bioactive components from chamomile species in porcine isolated blood vessels. Toxicol. Appl. Pharmacol. 272, 797-805. doi: 10.1016/j.taap.2013.06.021

Schwock, J., Dhani, N., and Hedley, D. W. (2010). Targeting focal adhesion kinase signaling in tumor growth and metastasis. Expert Opin. Ther. Targets 14, 77-94. doi: $10.1517 / 14728220903460340$

Sobin, L. H., Gospodarowicz, M. K., and Wittekind, C. (eds). (2009). TNM Classification of Malignant Tumours (UICC International Union against Cancer), 7th Edn. New York, NY: Wiley-Blackwell.

Stadler, S., Nguyen, C. H., Schachner, H., Milovanovic, D., Holzner, S., Brenner, S., et al. (2017). Colon cancer cell-derived 12(S)-HETE induces the retraction of cancer-associated fibroblast via MLC2, $\mathrm{RHO} / \mathrm{ROCK}$ and $\mathrm{Ca}^{2+}$ signaling. Cell. Mol. Life Sci. 74, 1907-1921. doi: 10.1007/s00018-016-2441-5

Teichmann, M., Kretschy, N., Kopf, S., Jarukamjorn, K., Atanasov, A. G., Viola, K., et al. (2014). Inhibition of tumor spheroid induced prometastatic intravasation gates in the lymph endothelial cell barrier by carbamazepine: drug testing in a 3D model. Arch. Toxicol. 88, 691-699.

Teisseyre, A., and Michalak, K. (2005). Genistein inhibits the activity of kv1.3 potassium channels in human T lymphocytes. J. Membr. Biol. 205, 71-79. doi: 10.1007/s00232-005-0764-5

Tsai, P. H., Cheng, C. H., Lin, C. Y., Huang, Y. T., Lee, L. T., Kandaswami, C. C., et al. (2016). Dietary flavonoids luteolin and quercetin suppressed cancer stem cell properties and metastatic potential of isolated prostate cancer cells. Anticancer Res. 36, 6367-6380. doi: 10.21873/anticanres.11234

Viola, K., Kopf, S., Huttary, N., Vonach, C., Kretschy, N., Teichmann, M., et al. (2013). Bay11-7082 inhibits the disintegration of the lymphendothelial barrier triggered by MCF-7 breast cancer spheroids; the role of ICAM-1 and adhesion. Br. J. Cancer 108, 564-569. doi: 10.1038/bjc.2012.485

Vogiatzoglou, A., Mulligan, A. A., Lentjes, M. A., Luben, R. N., Spencer, J. P., Schroeter, H., et al. (2015). Flavonoid intake in European adults (18 to 64 years). PLoS One 10:e0128132. doi: 10.1371/journal.pone.0128132

Vonach, C., Viola, K., Giessrigl, B., Huttary, N., Raab, I., Kalt, R., et al. (2011). NF-кB mediates the 12(S)-HETE-induced endothelial to mesenchymal transition of lymphendothelial cells during the intravasation of breast carcinoma cells. Br. J. Cancer 105, 263-271. doi: 10.1038/bjc.2011.194

Wei, J. F., Wei, L., Zhou, X., Lu, Z. Y., Francis, K., Hu, X. Y., et al. (2008). Formation of Kv2.1-FAK complex as a mechanism of FAK activation, cell polarization and enhanced motility. J. Cell Physiol. 217, 544-557. doi: 10.1002/jcp.21530

Woo, H. D., and Kim, J. (2013). Dietary flavonoid intake and risk of stomach and colorectal cancer. World J. Gastroenterol. 19, 1011-1019. doi: 10.3748/wjg.v19. i7. 1011

Wu, H. J., Wu, W., Sun, H. Y., Qin, G. W., Wang, H. B., Wang, P., et al. (2011). Acacetin causes a frequency- and use-dependent blockade of hKv1.5 channels by binding to the S6 domain. J. Mol. Cell. Cardiol. 51, 966-973. doi: 10.1016/j. yjmcc.2011.08.022

Zhao, G., Han, X., Cheng, W., Ni, J., Zhang, Y., Lin, J., et al. (2017). Apigenin inhibits proliferation and invasion, and induces apoptosis and cell cycle arrest in human melanoma cells. Oncol. Rep. 37, 2277-2285. doi: 10.3892/or.2017.5450

Zhou, P., Li, L. P., Luo, S. Q., Jiang, H. D., and Zeng, S. (2008). Intestinal absorption of luteolin from peanut hull extract is more efficient than that from individual pure luteolin. J. Agric. Food Chem. 56, 296-300. doi: 10.1021/jf072612+

Zhu, B. H., Ma, L., Pan, X. D., Huang, Y. L., and Liu, J. (2008). Scutellarin induced $\mathrm{Ca}^{2+}$ release and blocked KCl-induced $\mathrm{Ca}^{2+}$ influx in smooth muscle cells isolated from rat thoracic artery. J. Asian Nat. Prod. Res. 10, 583-589. doi: $10.1080 / 10286020801966633$

Conflict of Interest Statement: The authors declare that the research was conducted in the absence of any commercial or financial relationships that could be construed as a potential conflict of interest.

Copyright (C) 2018 Hong, Fristiohady, Nguyen, Milovanovic, Huttary, Krieger, Hong, Geleff, Birner, Jäger, Özmen, Krenn and Krupitza. This is an open-access article distributed under the terms of the Creative Commons Attribution License (CC BY). The use, distribution or reproduction in other forums is permitted, provided the original author(s) and the copyright owner are credited and that the original publication in this journal is cited, in accordance with accepted academic practice. No use, distribution or reproduction is permitted which does not comply with these terms. 